\title{
Interculturalidad en el discurso de los niños miskitos en Corn Island
}

\author{
Amanda Minks \\ Universidad de Oklahoma, EE.UU.
}

Junio, 2003. El lugar: Great Corn Island, a 52 millas de la Costa Caribe de Nicaragua. Algunos niños miskitos jugaban koko mana (un juego de bolita) en la tierra, fuera de sus casas en Brig Bay. Son primos, entre las edades de siete y once años, hijos y nietos de gente miskita que se mudaron a Corn Island desde la Costa Caribe de Nicaragua hace cuarenta años, más o menos. Algunos de estos niños nacieron en Corn Island y han pasado sus vidas allí. Otros se mudaron de comunidades miskitas de la costa a la isla Corn Island. Con frecuencia juegan con niños que viven cerca de familias creoles y mestizas y asisten a clases con otros niños miskitos, creoles y mestizos, desarrollando un amplio rango de habilidades lingüísticas a través de su interacción en la casa, el barrio, la escuela y la iglesia. Cada niño en este grupo tiene preferencias y habilidades un poco diferentes, pero todos tienen algún conocimiento de miskito, inglés kriol y español, las tres lenguas principales que se usan en Corn Island. ${ }^{1}$

Mientras los niños terminan el juego, su primo Aldrín llega y pregunta sobre los castigos que los perdedores habían recibido. ${ }^{2}$ En los juegos de koko mana en Corn Island, los perdedores reciben castigos leves tales como golpear sus nudillos con una bolita, o pegar con dos dedos en sus muñecas. Los niños llaman a estos castigos koko y tali (en el Pacífico le llaman "quemones"). A continuación, la transcripción de sus conversaciones. ${ }^{3}$

Símbolos de la transcripción:

Cursivas

Cursivas subrayadas

Romanas subrayadas

Romanas sencillas

Paréntesis

Paréntesis doble

Puntos

Llave

Flecha

Mayúscula
Miskito

Español

Inglés Kriol

Nicaragüense

Traducción

( ) Discurso poco claro

(( )) Comentario de la autora

... Elipsis

[ Discurso simultáneo

$\uparrow \quad$ Cambio de entonación

YO Con voz alta
1 Aldrin:

2 Lula:

3 Aldrin:

4 Coral:
An alki banghram?

¿Cuántos ((castigos)) recibieron?

Ya?

¿Quién?

\section{Man nani.}

Ustedes.

Faiv! Tu shi. ¡Cinco! A ella.

1 En este artículo uso la palabra "creole" para referirme a las personas que se auto-identifican con esta calificación étnica, mientras que cuando uso la palabra "kriol" me refiero al lenguaje que se desarrolló entre muchos de sus antepasados como un idioma de contacto, combinando elementos de idiomas africanos con el inglés y el español. La ortografia "kriol" se basa en el sistema ortográfico que han desarrollado en la Costa Caribe de Nicaragua para el idioma que habian llamado "creole english" o "miskito coast creole." En su estudio seminal, John Holm (1978) describió que este idioma está basado en la sintaxis africana, con el léxico principalmente del inglés, además de los idiomas africanos, del miskito y otros idiomas vecinos al igual que del español americano, que a su vez integró muchos términos de otros idiomas de América. (Agradezco a Danilo Salamanca por su sugerencia en este punto.) Por lo general siempre he usado la ortografia "miskitu" según el lenguaje y sistema ortográfico que usan en la costa caribe de Nicaragua, pero los editores de Wani han cambiado esto a "miskito" según la pronunciación y ortografia de esta palabra en su versión en español.

2 Todos los nombres de los niños son seudónimos.

3 Las transcripciones están basadas en grabaciones de audio de la interacción entre los niños. Transcribí las grabaciones en colaboración con personas multilingües en Corn Island. Yo empecé mis investigaciones con conocimientos básicos del idioma miskito y alcancé un nivel bastante fluido durante un año de investigaciones. Pasé tres meses conociendo niños miskitos y sus familias en Corn Island, antes de empezar a grabar sus actividades; creo que estaban bastante cómodos y no cambiaron su manera de hablar cuando les grababa. La transcripción del inglés kriol se basa en el sistema de ortografía que aparece en FOREIBCAIPILC/URACCAN 2003. 
5 Lula: Mariana ( ) an Coral wal. Mariana ( ) con Coral.

6 Ruby: Koko.

Koko.

7 Aldrin: $\quad$ Yang ra lika kumi sin ai daukras.

No me han hecho ni uno a mi.

8 Ruby: $\quad$ Mek ai giv yu wan.

Dejáme darte uno.

9 Aldrin: $\quad$ Mek ai giv yu firs.

Dejáme darte el primero.

10 Coral: $\quad$ No, yo firs, yo tali, tali, tali.

No, yo primero, yo tali, tali, tali.

11 Lula: $\quad \underline{\text { Duro. }}$

((Coral pega a la muñeca de Jeson con sus dedos))

12 Aldrin: $\quad$ Ah, dat is noting.

Ah, eso no es nada.
En esta conversación, Aldrín empezó con una pregunta en miskito. Lula le pidió en miskito que aclarara su pregunta, y él respondió en miskito. En la línea 4, Coral cambió al inglés kriol para contestar la pregunta original de Aldrín. Después Lula cambió a miskito de nuevo y ofreció más información sobre los castigos. En la línea 7, Aldrín ofrece un desafío en miskito, indicando que nadie le había impuesto un castigo. Ruby cambia al inglés kriol y propone darle ella el castigo, y él responde (en inglés kriol) con ser él el primero en darle a ella el castigo. En la línea 10, Coral hace una articulación híbrida en español e inglés kriol, repitiendo el término del juego tali que funciona en los tres idiomas. Hablando en español, Lula insta a Coral a que pegue a Aldrín duro. Coral le pega a la muñeca de Aldrín con sus dedos, y Aldrín responde con indiferencia en inglés kriol, "Ah, dat is noting" (eso no es nada).

El conocimiento de los lenguajes miskito, español e inglés kriol era un poco diferente para los niños en la conversación arriba. Aldrín y Ruby dominaron el miskito, porque habían pasado mucho tiempo en las comunidades miskitas en la Costa Caribe. En comparación con los otros niños, Coral tenía un poco menos de habilidad en miskito; sus padres generalmente le hablaban en español y ella no había pasado

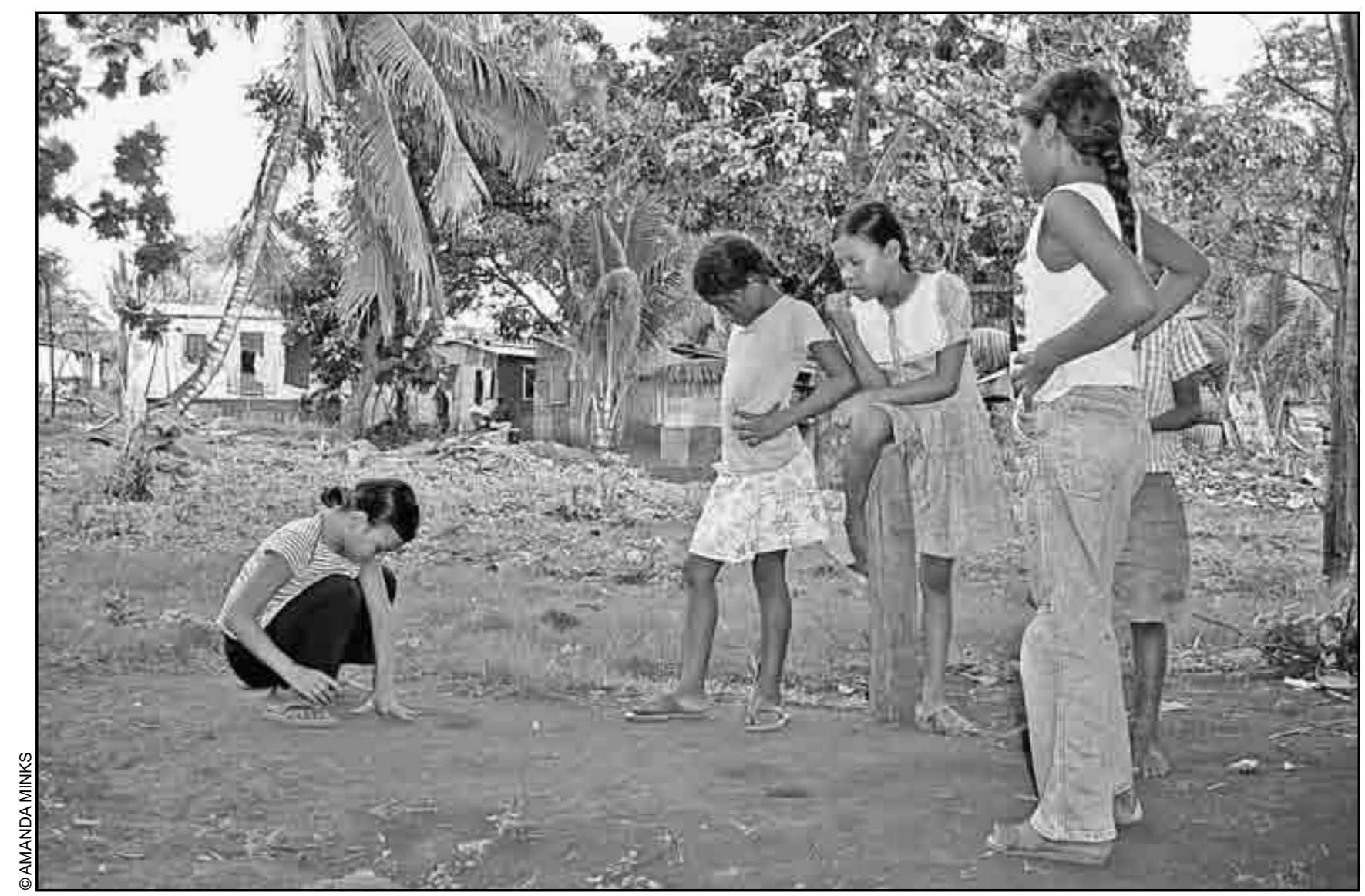

Jugando a la bolita. 
mucho tiempo en las comunidades miskitas. Sin embargo, Coral a veces hablaba bastante en miskito y entendía la mayoría de lo que escuchaba en este idioma.

Esta conversación es un ejemplo de lo que los sociolingüístas han llamado el cambio de códigos (o lenguajes), una forma de comunicación hábil y con frecuencia ingeniosa. El cambio de códigos puede facilitar la comunicación entre personas que tienen habilidades y preferencias lingüísticas que son distintas. A veces, los niños miskitos en Corn Island usaban los cambios de código para intensificar sus conflictos, para señalar cambios de hablante y contexto, y para llenar lagunas de conocimiento. Sin embargo, cambiar de código no siempre era una estrategia intencional entre los niños miskitos. Con frecuencia no había un motivo evidente para cambiar de código, y los niños no siempre reconocían las diferencias entre los lenguajes. Usaron la variedad amplia de recursos lingüísticos que existían en su comunidad para expresarse en la conversación cotidiana. Hablar lenguajes múltiples es una herramienta pragmática de comunicación en una comunidad multilingüe y, también. un símbolo de ser miembro de una comunidad multilingüe. Aunque uso el término "multilingüismo" por facilidad, el término más apropiado sería el concepto de "varilingüismo" elaborado por Valerie Youssef, el cual sugiere capacidades y pautas variadas de mezclar sistemas lingüísticos que pueden ser interrelacionados (Youssef 1996).

Con frecuencia, los hablantes de idiomas indígenas tales como el miskito parecen estar representados por una dicotomía de la pérdida o la revitalización del lenguaje. Esta dicotomía pasa por alto las maneras en que lenguajes múltiples pueden co-existir y transformarse el uno en el otro. El uso del lenguaje entre los niños miskitos en Corn Island es un ejemplo de la interculturalidad en la práctica. Generalmente, el término interculturalidad se ha usado en programas educativos y movimientos de revitalización en Nicaragua y en otras partes de América latina. Me gustaría presentar otro acercamiento a la interculturalidad, considerando cómo la interacción cotidiana de las personas en circunstancias de constante evolución puede crear nuevas formas de expresión e identidad. La interculturalidad no está solamente limitada a las interacciones multilingües, también abarca posiciones distintas del sujeto (el género, la raza, la etnicidad, la generación) y formas de mediación (la conversación cara-a-cara, la radio, la televisión, el teléfono, el internet).
Este artículo provee una introducción a mis estudios sobre la interculturalidad entre los niños miskitos que viven en Corn Island, basados en las investigaciones etnográficas y antropológica-lingüísticas que hice en 2002 y 2003. ${ }^{4}$ Las interacciones transcritas cuidadosamente demuestran cómo los niños miskitos combinan el conocimiento tradicional, el conocimiento mediático, el multilingüismo y el juego imaginativo, en su discurso cotidiano en Corn Island. Sugiero que la interculturalidad no sólo es una pedagogía promovida por las instituciones regionales y transnacionales; también es una práctica cotidiana de la comunicación basada en las historias de interacción e intercambio. El discurso oficial de la interculturalidad ha sido un medio de negociar la diferencia cultural en las instituciones educativas en la Costa Caribe de Nicaragua y en otros lugares. Sin embargo, la práctica de la interculturalidad surge en la interacción cotidiana que provee recursos autóctonos para el diálogo y la identidad.

En la próxima sección de este artículo hago una breve descripción cultural de Corn Island, luego una discusión sobre el uso del lenguaje entre los niños miskitos y sus contextos educativos. A continuación, una vista general del discurso transnacional de la interculturalidad amplía el marco teórico de este trabajo y sugiere nuevas direcciones para el discurso oficial de la interculturalidad en Nicaragua. En las dos secciones siguientes, los ejemplos del discurso de los niños miskitos demuestran cómo la interacción tanto monolingüe como multilingüe contribuye a la construcción cotidiana de la interculturalidad. Finalmente, en mi conclusión sugiero que las prácticas interculturales de la comunicación pueden ofrecer posibilidades para movimientos lingüísticos y culturales y formas de diálogo que fortalezcan la sociedad.

\section{Los miskitos en Corn Island}

La historia y la identidad pública de Corn Island están atadas profundamente a sus residentes creoles, particularmente las familias que tienen muchas generaciones en la isla. Corn Island era una de las comunidades originales de creoles, donde personas mezcladas de descendencia europea, indígena y africana empezaron a ser llamados "creoles" en los principios del siglo diecinueve (Gordon 1998). La población contemporánea de gente miskita tiene una historia relativamente reciente en Corn Island. Algunos pueden localizar sus historias familiares en

4 Yo realicé mis principales investigaciones en Corn Island cuando viví allá desde diciembre 2002 hasta septiembre 2003. Aunque he regresado a Corn Island muchas veces desde 2003, no he pasado bastante tiempo allá recientemente para entender la situación actual. Este artículo está principalmente limitado al marco temporal de 2002 y 2003. 
la isla a partir de los años de $1930 .^{5}$ Varios de estos miskitos se casaron con creoles, y sus niños empezaron a identificarse más como creoles; otros mantenían sus identidades miskitas. En los años de 1960 y 70 llegaron más miskitos para trabajar en las industrias de pescado y coco a Corn Island. La compañía pesquera "Promar" reclutó activamente trabajadores del lado de Puerto Cabezas en los años setenta. ${ }^{6}$

La transformación demográfica más dramática en Corn Island sucedió después de la revolución de 1979, cuando muchos isleños creoles salieron del país. El conflicto bélico de la contrarrevolución provocó que muchas personas de la Costa Caribe (creoles, miskitos y otros) huyeran a Corn Island para escapar de la violencia en sus comunidades de origen. En 1988, el huracán Joan destruyó las fincas de coco y la mayoría de los edificios en Corn Island, con el resultado de una dependencia mayor de la industria pesquera. La gente siguió mudándose a Corn Island no sólo de la Costa Caribe sino también del oeste de Nicaragua, y muchos encontraron trabajo en las compañías y barcos de pescado. La mayoría de los recién llegados no consiguieron títulos de propiedad para construir sus casas en Corn Island. Algunos pagaron alquiler, pero eran vulnerables al fraude por parte de personas que fingían ser dueños de la propiedad. Mientras los precios de los terrenos subieron con la promesa del desarrollo turístico, los barcos pesqueros de varias partes del mundo obtuvieron acceso al mar de la Costa Caribe, contribuyendo a agotar los recursos marinos.

Durante mis investigaciones en 2002 y 2003, las controversias sobre recursos marinos, propiedad, y narcotráfico crearon un ambiente tenso entre residentes de Corn Island. La nueva población creciente causó ansiedad entre los isleños creoles quienes añoraban el tiempo cuando conocían a todos los residentes de la isla. En 1971, la población de la isla era aproximadamente 2,000 habitantes. ${ }^{7}$ En 2003, la población era casi de 7,000 habitantes, además de otras personas que llegaron por corto plazo a trabajar o buscar trabajo en la isla. En este año, aproximadamente la mitad de la población era creole, un cuarto era miskito y el otro cuarto era mestizo. ${ }^{8}$ La adicción a las drogas y el robo afectaron a todos los sectores de la sociedad, incluso a las familias respetadas de la isla. Sin embargo, los barrios de migrantes en Brig Bay eran la fuente más grande de preocupación para las familias antiguas de la isla, porque las caras desconocidas podían facilmente esconderse en los populosos asentamientos. Los pobres viviendo sin título de propiedad en Brig Bay incluían familias miskitas, creoles y mestizas, pero los discursos públicos generalmente se enfocaron en los migrantes miskitos como un "problema". La competencia sobre escasos recursos en un ambiente de cambios socioeconómicos resultó en que mucha gente destacó la diferencia étnica en vez de los desafíos comunes que enfrentaban.

Aunque no siempre eran aceptados por la clase dirigente, los niños miskitos que nacieron y crecieron en Corn Island se consideraban a si mismos como isleños miskitos. Algunos regresaron de vez en cuando a las comunidades de sus padres en la Costa Caribe y gozaron de la oportunidad de interactuar con otros familiares y fortalecer su capacidad en el lenguaje miskito. Otros, nunca habían visitado las comunidades originarias de sus familias, y sintieron que su hogar verdadero era Corn Island, el lugar donde sus ombligos fueron enterrados según las costumbres de la región.

5 Esta aproximación se basa en entrevistas de historia oral que hice en Corn Island. En las primeras décadas del siglo veinte, a veces, la gente miskita llegaba de la Costa Caribe para trabajar en Corn Island, vender tortuga o venado. En 1908, el reverendo Edward Kelly, un residente de largo tiempo en Corn Island, anotó en su diario que "tres indios miskitos estaban en el culto" de la iglesia bautista en North End, sugiriendo que eran visitantes de corto plazo (Kelly sin fecha 32). Agredezco al reverendo Rodwell Morgan por brindarme una copia de este documento.

6 Entrevista, Luis Corea, 2003.

7 Según el Plan de Ordenamiento Ambiental del Municipio de Corn Island, la población de Corn Island en 1971 fue de 2,083 (Acuña Roque et al 2002). Este documento refiere a un texto anterior llamado Plan de Acción para el Manejo de Recursos Naturales del Municipio de Corn Island, Lacayo González et al 1999.

8 Este cálculo está basado en una encuesta habitacional dirigida por el Ministerio de Salud en Corn Island entre 2003 y 2005. Documentaron un total de 6,801 residentes relativamente fijos en Corn Island. De estos, 3,530 eran creoles; 1,580, mestizos, y 1691 eran miskitos. 


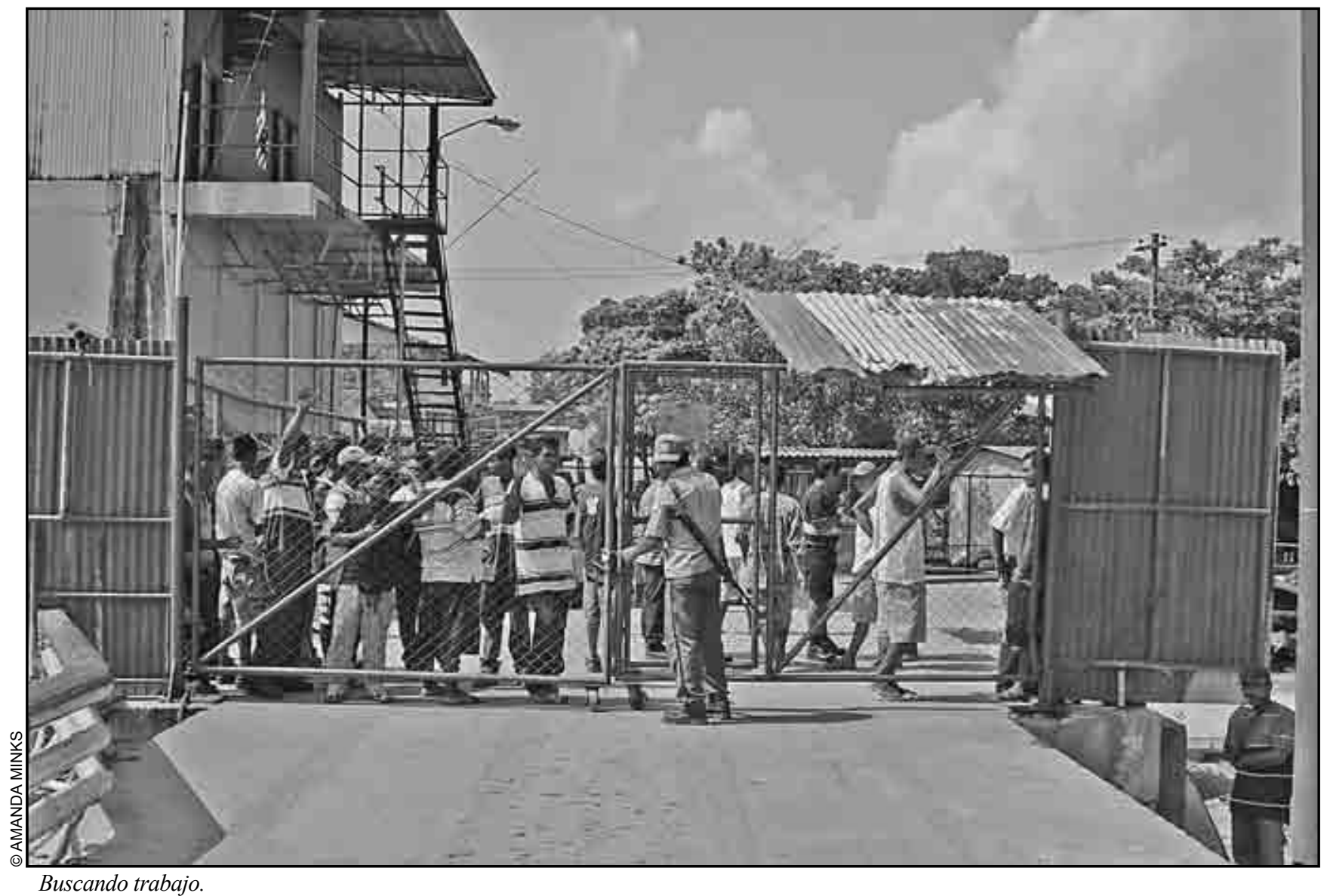

\section{Senderos multilingües}

La mayoría de la gente miskita en Corn Island vivía en Brig Bay, donde el lenguaje miskito se hablaba con frecuencia en los espacios públicos, los juegos de niños, la iglesia y la escuela morava. Los hablantes miskitos de comunidades en la RAAN (Región Autónoma del Atlántico Norte) continuaron llegando a Corn Island por corto plazo y contribuyeron a la vitalidad de la comunicación miskita. Algunos niños mestizos cuyas familias se habían mudado del oeste de Nicaragua también llegaron a dominar el miskito a través de sus interacciones con niños miskitos en el barrio.

Aun dentro de una sola familia miskita en Corn Island, las personas mostraron con frecuencia bastante variación en sus habilidades y preferencias lingüísticas. Esta variación surgió de pautas distintas en la socialización del lenguaje, las historias de migración, la asistencia en la escuela y las afiliaciones del grupo de pares. Una familia que crió siete niños en la isla es un ejemplo de esta variación. Los cuatro niños mayores empezaron con el miskito como su primer lenguaje y aprendieron el español en la escuela. El tercer niño, que por ser varón tenía bastante libertad de recorrer y conocer niños de otros barrios, de pronto desarrolló fluidez en inglés kriol. Con el quinto niño pasó igual. (La mayoría de las niñas en esta familia también aprendieron el inglés kriol pero con un paso más lento por las limitaciones de movimiento de niñas.) Cuando el quinto niño estaba creciendo, los padres decidieron hablar a sus niños menores sólo en español, con la intención de facilitar su éxito educativo. La sexta niña habló casi únicamente español. Cuando la séptima niña era pequeña, algunas primas cercanas en edad llegaron de las comunidades miskitas para vivir con la familia en Corn Island, aumentando así el habla miskita entre los niños. Las dos niñas menores también tenían la influencia de amistades que formaron en una escuela privada en el otro lado de la isla. Una tenía amistades principalmente con niñas que hablaban español, y ella continuó siendo español-dominante. La hija menor (la "cumiche") tenía amistades con niñas que hablaban inglés kriol, y ella desarrolló igual habilidad para el español y el inglés kriol, además de bastante capacidad en miskito. 
El uso del lenguaje en la familia cambió un poco cuando la segunda hija se fue a estudiar a Bluefields - la ciudad con mayor cantidad de hablantes del inglés kriol en la Costadurante su juventud. Su capacidad en el inglés kriol se mejoró allá, y cuando regresó a Corn Island resolvió hablar en inglés kriol a su primera hermana menor, para seguir practicando, pero siempre hablaba a sus otras hermanas menores en español, para ayudarles en la escuela. La pauta de habilidades del lenguaje entre sus familiares no ha sido totalmente un cambio del miskito al español o al inglés. Un primo que creció en una casa vecina empezó su niñez como hablante kriol-dominante con capacidad de entender el miskito. Su padre era bilingüe en miskito e inglés kriol, pero pensaba que el inglés kriol serviría mejor al futuro de sus hijos. Sin embargo, en los años ochenta, sus padres se metieron en los movimientos culturales en la costa y reevaluaron su capacidad en miskito. Comenzaron a hablar a sus hijos principalmente en miskito, y su hijo joven se hizo un hablante fluido del miskito.

Las investigaciones de Mark Jamieson en Kakabila en los últimos años de 1990 son otro ejemplo de la fluidez y diversas direcciones de la socialización del lenguaje en la Costa Caribe. En Kakabila, una comunidad históricamente miskita en la cuenca de Laguna de Perlas, los niños con frecuencia hablaban kriol, pero comenzaron a hablar más miskito cuando llegaron a ser adolescentes y adultos con los derechos y las responsabilidades que esto conlleva (Jamieson 1995, 1999, 2001, 2007). Usaron las estructuras morfológicas y morfo-sintácticas del miskito para adaptar nuevas palabras prestadas y crear maneras híbridas de hablar. Esas técnicas también eran comunes en Corn Island, pero algunas familias (particularmente las de la RAAN) mantenían variedades más conservadores del habla miskita, porque tenían más comunicación cercana con los hablantes miskitos de la región Norte. La mayoría de la gente miskita de la RAAS (región Sur), particularmente la cuenca de Laguna de Perlas, tenían historias continuas de interacción con personas creoles y con el inglés kriol, y esa gente cruzó un poco más fácilmente los límites culturales y lingüísticos en Corn Island.

El artículo de Jane Freeland en Wani en 2004, sugiere que este tipo de fluidez es común entre muchos grupos en la Costa Caribe. Ella describe autobiografías de costeños moviéndose entre lenguajes e identificaciones en repertorios "plurilingües" que incluyeron miskito, inglés kriol, inglés “estándar," español, ulwa y sumu/ mayangna. En algunos casos, los hablantes ampliaron sus repertorios para incluir lenguajes más poderosos tales como español, inglés, inglés kriol y miskito, en sus ambientes educativos y laborales, pero después de un tiempo re-enfatizaron su habilidad e identificación con sus lenguajes ancestrales. En otros casos, los hablantes crecieron en familias o comunidades bi- o multilingües donde el uso del lenguaje fue formado por su preferencia personal y relaciones sociales más que por una jerarquía fija de idiomas. En varios casos, los nuevos tipos de empleos y capacidades que se hicieron valiosos bajo el régimen de autonomía resultaron en la re-afirmación de estas capacidades multilingües (Freeland 2004).

Freeland indica que muchas veces la fluidez de repertorios plurilingües no encaja bien con la rigidez de programas educativos "bilingües" que son adaptados de un modelo internacional. En Corn Island, durante mis investigaciones, las escuelas públicas recibieron apoyo del Ministerio de Educación para clases y materiales bilingües en inglés y español según el paradigma del Programa Regional de Educación Intercultural-Bilingüe (EIB). Las clases diseñadas para estudiantes creoles generalmente han usado textos en inglés estándar, mientras que la mayoría del discurso oral está en kriol. ${ }^{9}$ En años recientes ha surgido un movimiento para estandardizar una ortografía (sistema de escribir) el inglés kriol y producir algunas publicaciones en inglés kriol también. En Rigoberto Cabezas, la escuela pública de Corn Island donde muchos estudiantes miskitos asistieron a clases, la colocación de los niños miskitos en aulas "bilingües" (en inglés y español) o "nacional" (sólo en español) dependía de sus propias preferencias, solicitud de los padres, opinión de los profesores y la disponibilidad de espacio. Algunos niños miskitos con bastante capacidad en inglés kriol podían adaptarse muy bien a las clases en inglés. Para otros niños miskitos con poca capacidad en el inglés kriol era un desafío entender un discurso oral en inglés kriol y un discurso escrito en inglés estándar. ${ }^{10}$

\footnotetext{
9 El término "inglés estándar" en este artículo no implica un idioma que es más correcto o que tiene un rango más amplio. El inglés kriol de Nicaragua es igualmente sistemático, aunque puede ser más flexible siguiendo el continuo creole entre variedades del basilecto, mesolecto y acrolecto. El inglés kriol también es un idioma internacional, puesto que comparte muchas caracteristicas con otros tipos de inglés creole del Caribe y se puede comunicar con una esfera amplia de personas de la diáspora del Caribe anglófono.

10 El sistema de ortografía en inglés kriol parece mejor adaptado para facilitar la alfabetización entre hablantes del miskito además del kriol, pero este sistema no se usaba mucho durante el tiempo de mis investigaciones.
} 


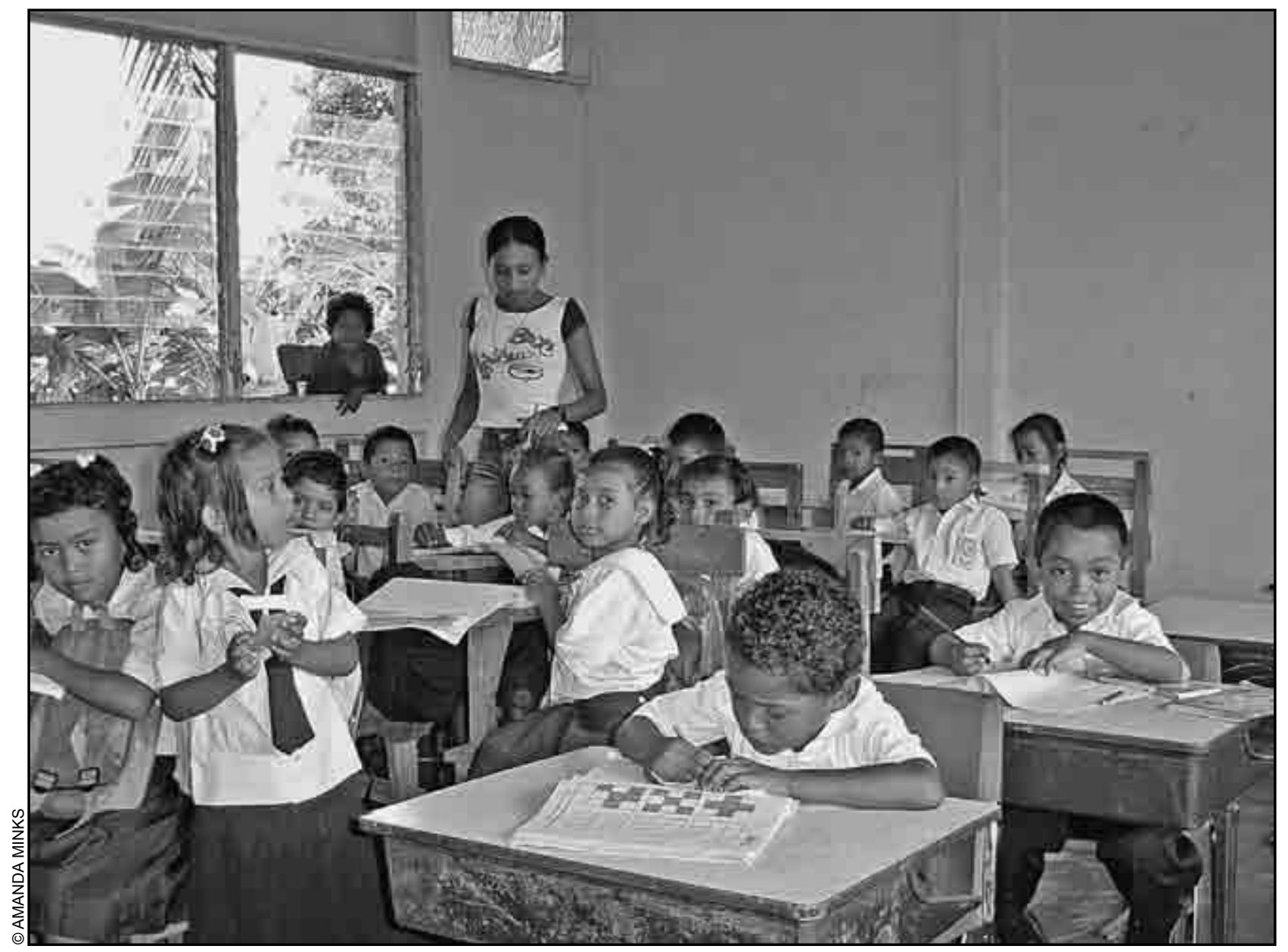

Una clase de prescolar en la escuela morava.

En 2003, el miskito fue establecido como un lenguaje oficial del discurso en los grados menores de la semiprivada escuela morava de Corn Island, a través de un proyecto de educación intercultural-bilingüe que operó en la Costa desde 2000 hasta 2004. El proyecto FOREIBCA (Fortalecimiento de la Educación Intercultural Bilingüe de la Costa Atlántica) fue apoyado por el gobierno de Finlandia y fue ejecutado en colaboración con dos organizaciones nicaragüenses: el Ministerio de Educación, Cultura y Deportes (MECD), y el Instituto de Promoción e Investigación Lingüística y Rescate Cultural (IPILC), que es parte de la Universidad de las Regiones Autónomas de la Costa Caribe Nicaragüense (URACCAN). En la escuela morava de Corn Island, el programa EIB se volvió trilingüe porque los padres y profesores escogieron una política de usar el miskito, el español y el inglés kriol en las aulas, así como muchos niños ya lo hacían en su vida cotidiana. FOREIBCA proporcionó talleres en la formación de profesores y materiales del currículo para el programa EIB en la escuela morava de 2003 a 2004. Los nuevos textos en miskito ayudaron a los estudiantes miskito-hablantes a aprender a leer y escribir, y a otros hablantes a aprender el miskito. La mayoría de los estudiantes en la escuela morava durante este tiempo eran miskitos, pero otros eran creoles y mestizos que vivían cerca. Los padres mestizos y creoles que enviaron sus hijos a la escuela morava, también apoyaron la integración del miskito al currículo. Algunos de sus hijos ya habían aprendido un poco (a veces bastante) miskito en sus grupos de pares, y otros querían que sus hijos aprendieran un idioma que les sería útil para su futuro en la Costa Caribe. Los nuevos libros y políticas de la escuela morava apoyaron los retos de la interculturalidad, incluso, el respeto mutuo para diferentes tipos de personas y formas de conocimiento, además del diálogo entre éstos.

Interculturalidad es un lema común en discursos educativos y públicos en la Costa Caribe de Nicaragua, y parece una manera lógica de conceptualizar las fluidas y múltiples formas de socialización del lenguaje que he descrito. En la próxima sección examinaré el concepto de interculturalidad, tal y como se ha desarrollado en América latina y en Nicaragua. 


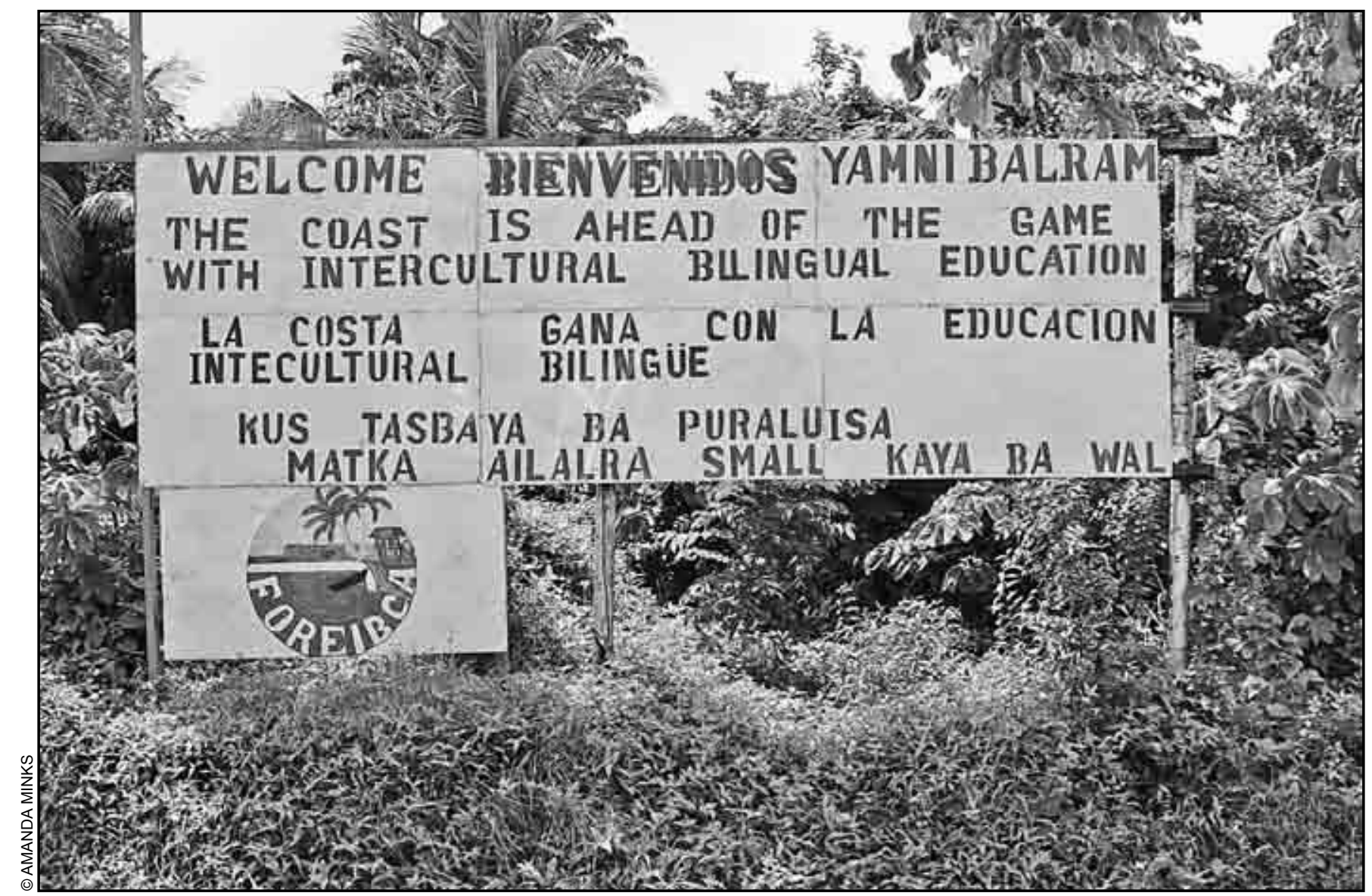

Un letrero en Corn Island promoviendo la educación intercultural-bilingüe.

\section{Interculturalidad}

Durante los años 1980 y 90, el concepto de interculturalidad surgió como una manera de hablar sobre las relaciones interdependientes entre grupos culturales, en América latina, y su ubicación en nuevos regímenes de ciudadanía (Fuller 2002; Walsh 2006). En parte era una crítica de los discursos norteamericanos del multiculturalismo, que sugirieron la co-existencia de "culturas" relativamente rodeadas, identificadas por un conjunto de prácticas que incluían el idioma, la música, el baile, la comida y el estilo de vestir. El multiculturalismo norteamericano promovió la "tolerancia" y la representación de la "diversidad," pero ocultó los fundamentos de la exclusión tales como el acceso al conocimiento y a los recursos económicos. La interculturalidad se movió más allá de la inclusión simbólica para promover el "diálogo" y una política de transformación en las relaciones entre la diferencia cultural y la desigualdad social (Tubino 2002). La reforma de la educación fue un contexto clave para realizar la interculturalidad en la práctica, particularmente a través de los intentos para integrar formas indígenas del conocimiento y expresión, en las instituciones regionales y nacionales (Godenzzi 1996). El proyecto más grande del activismo intercultural ha sido ampliar las nociones de ciudadanía y la participación democrática que permitan la inclusión de la diferencia cultural en una "comunidad política multicultural" (García 2005:165). Como ha señalado Jane Freeland, una de las ironías de este proyecto es que la educación "intercultural," con la meta explícita de fortalecer los lenguajes y formas de conocimientos locales, se ha vuelto un modelo transnacional que se adapta a diferentes contextos nacionales. Este modelo promueve un programa "bilingüe" que conceptualiza grupos separados e internamente homogéneos que interactúan con la cultura nacional (Freeland 2004).

Algunos antropólogos latinoamericanos han desarrollado otro acercamiento a la interculturalidad. Néstor García Canclini y Alejandro Grimson describen la interculturalidad como un término analítico enfocado en la construcción de límites entre (y dentro de) grupos sociales, con frecuencia a través de la lucha (García Canclini 2004; Grimson 2000). Este planteamiento sigue un cambio, en las ciencias 
sociales, hacia la interpretación de la diferencia cultural como una construcción activa en vez de una herencia pasiva o lista de rasgos. Sin embargo, la interculturalidad también tiene que ver con las maneras en que mucha gente usa discursos sobre la cultura, para proyectos políticos, a veces usando las mismas listas de rasgos que muchos antropólogos han descartado. Los significados múltiples de la interculturalidad abarcan no sólo los planteamientos constructivos, sino las ideas de la autenticad y el primordialismo que puede difundirse por los movimientos indígenas y los discursos públicos en general.

En América latina, entonces, la interculturalidad es un término disputado que se mueve entre los discursos esencialistas y constructivistas, entre la teoría y la práctica, entre los proyectos populares e institucionales. En lugares tales como Nicaragua y el Perú, la educación intercultural abrió una plataforma para los movimientos indígenas luego de guerras civiles, cuando la mayoría de los caminos de proyectos políticos fueron cerrados (Freeland 1993, 1995; García 2005). Para activistas indígenas en Colombia, la interculturalidad ha sido un proceso de apropiar ideas, de una cultura a otra, para construir una ciudadanía indígena dentro de una nación pluralista (Rappaport 2005). Para algunos teóricos sociales, la interculturalidad se ha movido mas allá de los discursos de la hibridad para teorizar más directamente las relaciones entre la diferencia cultural y la desigualdad social (García Canclini 2004, 1995). Sin embargo, los gobiernos y las organizaciones internacionales también se han apropiado de discursos de la interculturalidad, para manejar y controlar la diferencia, ocultando tensiones y desigualdades (Hale 2005; Postero 2006). Los burócratas y aún los activistas culturales pueden estar alejados de las luchas cotidianas de la gente que está por debajo de las jerarquías sociales, que pueden sentirse separados de los proyectos culturales supuestamente realizados para beneficio de ellos mismos.

Podemos considerar los discursos de la interculturalidad como parte de las luchas históricas más amplias sobre las formas y los significados de la mezcla cultural y de la autenticidad, cristalizados en los términos de "mestizaje," "creolización" e "indigenismo". Estos términos no sólo son categorías empíricas, sino que a menudo son narrativos de autenticidad que tienen significado al establecer un contraste con la gente y las prácticas que caen fuera de sus límites (Palmié 2006). En muchas partes de América latina y el Caribe, los sujetos nacionales se han construidos como "mestizos" (en países hispano-hablantes) o "creoles" (en el Caribe anglófono y francófono), mientras que ciertos tipos de personas quedan excluidas de estas categorías (Khan 2001).
El indigenismo puede ser reivindicado por una variedad de movimientos y no es sinónimo de pueblos indígenas, a quienes se les ha negado la ciudadanía en algunos lugares donde tienen las historias más largas de residencia. En Nicaragua, la exclusión de los pueblos de la Costa Caribe (tantos "indígenas" como "étnicas") del proyecto de construir la nación basado en la zona del Pacífico contribuyó a la construcción de la imagen nacional. Como escribe Justin Wolfe, la Costa Caribe "sirve de contraste al discurso del mestizaje realizando la imagen de homogeneidad en Nicaragua" (Wolfe 2007:162, mi traducción). Aún dentro de los discursos del mestizaje nacional, las divergentes prácticas culturales siguieron desmontando la nación (Gould 1998). El surgimiento de los discursos latinoamericanos sobre la interculturalidad, en las últimas décadas del siglo veinte, era una manera de evaluar la heterogeneidad cultural que resistió los proyectos de construir la nación.

En Nicaragua, interculturalidad se interpreta con frecuencia como el mantenimiento de la diferencia cultural, además de la interacción y el diálogo entre los distintos grupos culturales. En los discursos públicos, los grupos culturales generalmente son definidos por las prácticas culturales tales como el lenguaje, la comida y el estilo de vestir. Las presentaciones folclóricas hacen explícitas estas asociaciones. También, los proyectos de revitalización cultural y lingüística han sido una parte importante del discurso de la interculturalidad; estos proyectos han intentado re-construir las prácticas del pasado y fomentar su uso presente y futuro. Los proyectos de revitalización con frecuencia adoptan una actitud purista, por ejemplo, aspirando a eliminar los elementos extranjeros de los idiomas indígenas, y oponiendo el cambio y la mezcla de códigos lingüísticos. Bajo estas condiciones, las personas pueden desarrollar registros formales para el uso del discurso público y la escritura. El "fortalecimiento de lo propio" ayuda a la gente a mantener las prácticas tradicionales que forman su identidad, y usar la tradición como un recurso valioso en un mundo de globalización (Walsh 2006).

No obstante, la práctica cotidiana con frecuencia no es restringida por estas correlaciones entre el lenguaje, la etnicidad y la cultura. Muchos costeños son multilingües y tienen múltiples descendencias y prácticas culturales. A veces, las personas cambian sus prácticas lingüísticas e identificaciones culturales durante sus vidas. No sólo es un movimiento de dirección única hacia la asimilación. El proyecto político de la autonomía ha apoyado la revalorización de las culturas y lenguajes costeños, impulsando a mucha gente a renovar sus lenguajes de herencia y transmitirlos a sus hijos. A la vez, las personas pueden continuar sus prácticas cotidianas de la mezcla 
lingüística. Aunque el contacto y la mezcla de lenguajes pueden resultar en la transformación de sistemas lingüísticos, estos procesos no siempre resultan en la pérdida de lenguajes ancestrales.

Una interpretación alternativa de la interculturalidad nos ayuda a comprender estas formas heterogéneas del lenguaje, por considerar cómo se realiza la comunicación usando un fondo diverso de recursos. La diferencia y la variación siempre han existido dentro de grupos culturales - las mujeres y los hombres, por ejemplo, generalmente son socializados de maneras distintas y ocupan diferentes posiciones en la sociedad, aún cuando se afanan por la igualdad. Pero la interculturalidad es un concepto particularmente útil para entender nuevas formas de interacción y diferenciación que han surgido en una época de globalización. La interculturalidad no sólo tiene que ver con la fortaleza de lenguajes ancestrales. También se trata de la creación de nuevas formas de expresión a través de las cuales la gente puede adaptarse a circunstancias en procesos de cambios. Aún en los proyectos de revitalización lingüística, la gente puede inventar o adaptar términos indígenas para describir nuevos objetos (tales como "computadoras") y nuevas ideas (tales como "autonomía").

\section{Los medios y la cosmovisión}

El ejemplo de Corn Island puede mostrar las maneras en que nuevas formas de interacción e identificación surgen en la práctica, sin la pérdida total del lenguaje y de la cultura. Los niños con frecuencia están a la vanguardia de los cambios culturales, porque crecen en un mundo un poco distinto al mundo en el cual crecieron sus padres. Los niños que estudié en Corn Island eran miembros de la primera generación de sus familias que crecían con televisión con cable. Algunos padres y educadores estaban preocupados por los efectos de la televisión en el comportamiento de los jóvenes (particularmente en cuanto a las normas del género y de la sexualidad), pero la televisión no causó un gran cambio del lenguaje. Los niños, a menudo hablaban miskito mientras miraban la televisión en inglés o español, y usaron marcos culturales tradicionales para interpretar lo que vieron.

Considerando lo lejos que Corn Island queda de las comunidades miskitas, en la Costa Caribe, era notable la continuación de muchas prácticas culturales en Corn Island. Algunos niños pequeños se encontraron totalmente rodeados por el habla miskita hasta que entraron a la escuela. En la escuela morava, los niños seguían usando el miskito dentro y afuera del aula, aún antes de la implementación del programa de educación intercultural. ${ }^{11}$ Los líderes de la iglesia morava mantenían el miskito como la lengua principal del culto, y algunos usaban a propósito el sistema tradicional de los números miskitos, que era poco común en la conversación cotidiana (la mayoría de los hablantes miskitos usan términos numéricos adaptados, hace mucho tiempo, del inglés estándar y el inglés kriol). La mayoría de las familias incluía personas con conocimiento de la medicina tradicional. Algunos especialistas tenían pericia en las prácticas tantos espirituales como medicinales - el campo tradicional del sukia.

Para la gente miskita en Corn Island, como en muchas comunidades, la fisiología y la espiritualidad están entrelazadas a través de la cosmología y la práctica cotidiana (Cox 1998). Las rutinas y senderos diarios de los niños se estructuraron por su conocimiento de lasa o setan nani — seres espirituales - que animaron el paisaje y se metieron en los asuntos humanos (Offen 1999). Los niños crecieron escuchando las historias de los mayores sobre encuentros con espíritus en otras comunidades. Algunos de estos espíritus también ocuparon Corn Island, como swinta o duhindu (duende) y liwa (sirena). En un lugar como Corn Island, donde el robo era común y los desconocidos estaban siempre presentes, uno de los espíritus más prominente era el urus (mono). Este ser generalmente tenía la forma de un humano, pero consiguió poderes mágicos para transformarse a través de la comunicación con espíritus malos en el panteón. El urus fue culpable de algunos robos y otras delincuencias, particularmente durante el tiempo de lluvia, cuando era más fácil evitar la atención. ${ }^{12}$

11 Durante el tiempo de mis investigaciones, muchos niños miskitos asistían también a la escuela pública más grande, pero el lenguaje miskito no era tan común ahí. Ninguno de los profesores podía hablar el miskito, y sólo los niños miskitos más pequeños hablaban miskito entre ellos. En años recientes he escuchado que la población de estudiantes miskitos en la escuela pública ha aumentado tanto que se sienten más cómodos hablando miskito informalmente en la escuela, aunque todavía no hay enseñanza formal en miskito, según mi información en esta fecha.

12 A veces, la diferencia entre espíritus traviesos y los ladrones mundanos no es muy clara. Por un tiempo, me quedaba en un cuarto que supuestamente era visitado por un lalkas, un ser sin cabeza que podría estrangular a la gente mientras dormía. Una noche desperté y vi la sombra de una mano en la ventana que quedaba arriba de mi cama, lo cual me asustó bastante. Sin embargo, esa noche es probable que no haya sido el lalkas, puesto que al día siguiente me di cuenta que varias cosas habian desaparecido, incluso mi toalla, que estaba colgada en la ventana. 


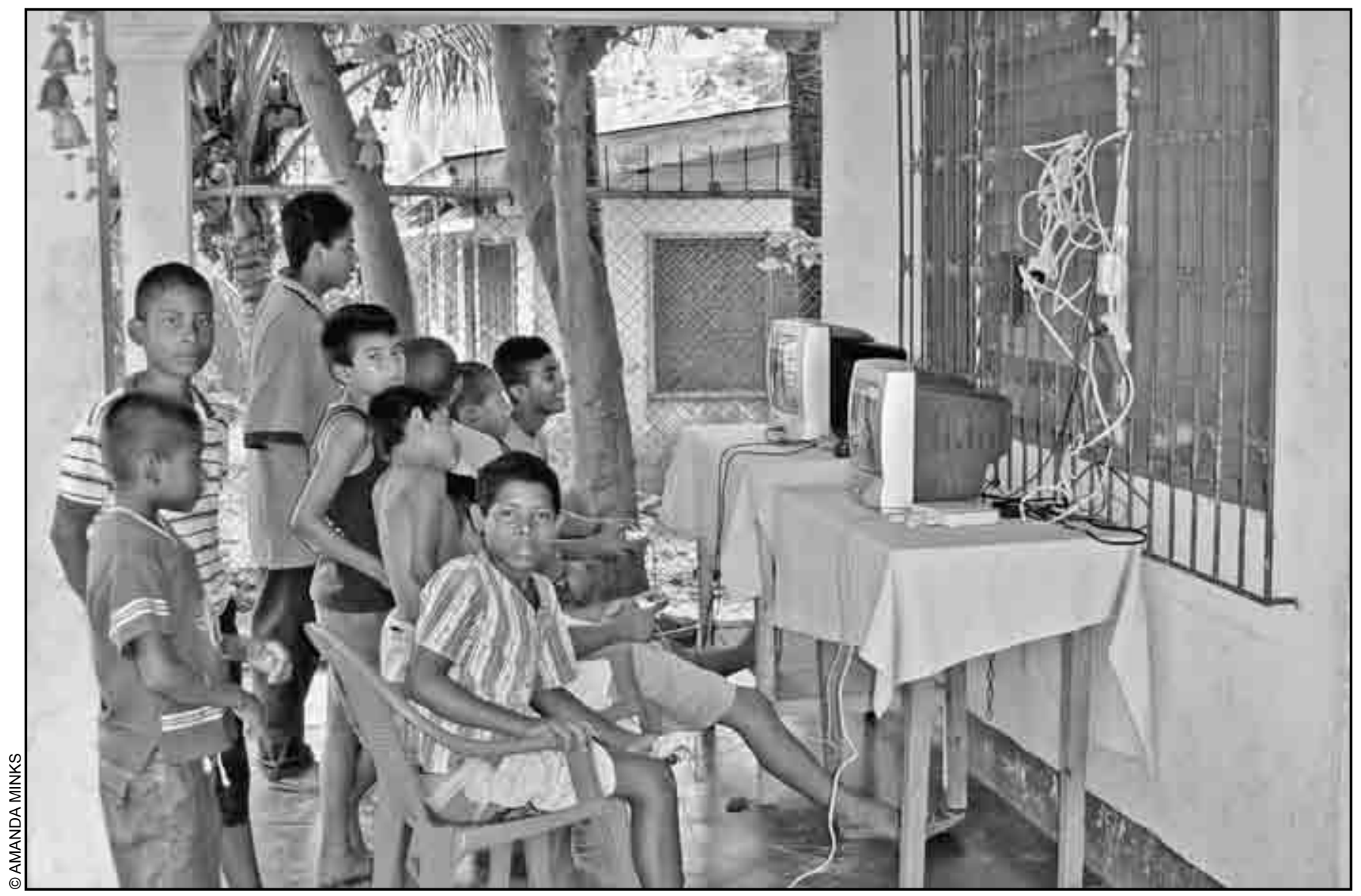

Niños de Corn Island jugando Nintendo.

Los niños miskitos sabían donde los espíritus malos tendían a estar al acecho en Corn Island, y los mayores siempre los advirtieron de evitar estas áreas aún si tenían que pasar por una vía más larga. Los encuentros con seres espirituales podrían resultar en la desaparición, la enfermedad o hasta la muerte. Un sendero detrás de la escuela morava fue, con razón, objeto de bastante miedo por ser un sitio de espíritus y actos malvados. Unos cuantos años antes, una niña miskita fue violada y asesinada en ese sendero, y algunos niños que pasaron por esta área se enfermaron. Cuando un niño se enfermaba, con frecuencia echaban la culpa a un setan o lasa. Generalmente, el remedio era una combinación de medicina natural del monte y un viaje al hospital para una inyección.

Los encuentros con seres espirituales eran revividos a través de narraciones que pasaron de una generación a la otra en las familias. Estas historias eran herramientas importantes para socializar a los niños en pautas seguras del comportamiento. Los encuentros con espíritus no eran fábulas que se creaban para el beneficio de los niños, sino experiencias reales que contaban para enseñar a los niños los peligros que existían en el mundo. Cualquier persona podría contar una historia sobre un encuentro con espíritus, aún si no lo había experimentado personalmente. Los niños contaban historias que habían escuchado de los mayores, y sus propias historias sobre encuentros con espíritus.

En la siguiente transcripción, dos primos, Derek y Nildo, me contaron de un encuentro que la madre de Derek había experimentado con una liwa mairin (sirena femenina) en la Costa Caribe cerca de Awastara. Derek había crecido principalmente en Awastara y su habilidad en español e inglés kriol era poca; estaba recién llegado a la isla para una visita de varios meses. Nildo había crecido en Corn Island. Generalmente hablaba inglés kriol con sus hermanas y la abuela que lo criaba. Sin embargo, Nildo también escuchaba y hablaba bastante miskito (su abuela hablaba miskito con Derek y con sus vecinos) y español (su abuelo era mestizo). Ambos niños hablaron en miskito en esta conversación, lo cual demuestra la resistencia del conocimiento lingüístico y cosmológico ante las nuevas experiencias culturales y mediáticas.

Mientras Derek narraba la historia sobre el encuentro con la liwa mairin, Nildo interrumpió con algunas descripciones 
generales de las características de este ser, probablemente para mi beneficio. En la línea 14, Derek empezó otra narración sobre un encuentro con una liwa mairin que había visto en la televisión.

1 Derek: Bahara mamiki tihmia yu kum tihmia let let kan,

Un día ahí mi mama en la noche, en la noche que era muy tarde,

2

TIHmia ALkan, tihmia alkan taim, liwa mairin kum, aihtabi kan an na kat klauhwi kan,

Se oscureCIO, cuando se oscureció, una sirena, se estaba bañando y hasta aquí estaba brillando,

3

nakra ba INGNI taki kan. Lebn aklak ba kaikaia klauhwa laik ba?

sus ojos estaban ilumiNADos. A las once, ves, les gusta brillar?

Kaiki, jas, witin KLI dimwan ai lal wal. DIman, kli mamiki bal luan?

Mirando, solamente, ella de NUEVO entró ((el mar)) con su cabeza. EntRO, de nuevo mi mama pasó?

5

Diara $\uparrow$ munras kan mamiki ra.

No $\uparrow$ hizo nada a mi mama.

6 Nildo: $\quad$ Aha, ba nani, ba nani kabu ra [bilara ba? Aja, ellos, ellos están [en el mar?

7 Derek: [An kuku brihwi swiuya, [Y llevando un coco lo dejan,

8

kuku upla want kan na laka, ba mihta brihwi swin.

una persona quería un coco así, por eso lo llevaron y lo dejaron.

9

An witin flaslaitka, flaslaitka apu kaka witin ban daukan.

Y su foco, si no tenía un foco lo hizo así.

10 Nildo: Bara, ba nani laik apu sa em, upla ai waika kaikbia upla dauk bribia ba, Entonces, no les gusta, em, que la gente vieran que tienen colas, witin nani ba upla. Kuna upla, pat nu sa [ba nani

ellos son personas. Pero la gente, ya sabe [sobre ellos.

12 Derek:

[Witin samtaim ba, witin?

[Ella a veces, ella?

Samtaim ba witin prak dimisa samtaim witin prak taki?

A veces ella ((la sirena)) se pone un vestido, a veces ella sale con un vestido?

Yu KUM yang tele ra KAIkri, tele ra. Tele ra kaikri taim, tele ra kaikri taim, UN día yo VI en la tele, en la tele. Cuando vi en la tele, cuando vi en la tele.

waitnika? Sin waitnika li bilara dimui taim baha mairka, el hombre? Cuando el mismo hombre estaba entrando el agua esa mujer,

mairin wal wasata baha wal prias ra WAN. con la mujer salió con ella, FUERON al culto.

An bal kahwan taim liwa mairin kan. Y cuando vino y se cayó se convirtió en sirena.

En esta transcripción, el uso continuo del miskito por Nildo, particularmente, demuestra que el multilingüismo no siempre hace interferencia con el mantenimiento del conocimiento indígena, tanto lingüístico como cultural. La coexistencia de dos historias, una pasada por la familia y otra vista en la televisión, también demuestra las maneras que el conocimiento cultural ayuda a los niños para tender un puente entre diferentes tipos de experiencia. En las narraciones de espíritus que son contadas entre los miskitos, en el pasado remoto, es posible que la liwa mairin tomara una forma diferente que la representación occidental de la sirena o "mermaid." Sin embargo, Derek podría reconocer la figura que vio en la televisión y compararla a la figura que su madre y la abuela habían descrito en Awastara. La historia transmitida en su familia le ayudó a interpretar la escena que vio en la televisión dentro de un marco cosmológico miskito. El conocimiento cultural miskito se volvió una herramienta útil para participar en los medios globales de comunicación. Esto es un ejemplo de la interculturalidad en la práctica. 


\section{Multilingüismo y medios de comunicación en el juego fingido}

En su juego fingido en Corn Island, los niños miskitos a veces actuaron como personajes de la televisión, pero con frecuencia usaban bastante miskito en estas actividades. En la siguiente transcripción, un grupo de niños entre las edades de siete y once años estaban jugando a la escuelita. Ruby (10 años) estaba actuando en el papel de la maestra Carluta, adaptado del programa mexicano Cero en Conducta. Los otros niños eran sus estudiantes. Cuando se comportaron mal por copiar sus respuestas uno al otro, Ruby los llamó "Chavo" (línea 7) y "Chilindrina" (línea 21), personajes del programa mexicano El Chavo del Ocho.

Ninguno de estos niños estaba en las clases interculturales-trilingües de la escuela morava, aunque algunos de sus hermanos menores asistían a estas clases. Para los niños, en este ejemplo, la mayoría del discurso oficial en sus clases era en español. También el español era el lenguaje de las clases representadas en los programas Cero en Conducta y El Chavo del Ocho, los cuales eran un recurso para el juego. Sin embargo, no hablaron español exclusivamente cuando estaban jugando a la escuelita. Como demuestran las transcripciones, ellos mezclaron el español con el miskito y a veces con el inglés kriol.

\section{Ruby: $\quad$ Apúrense! Cuando yo vengo de orinar Ustedes ya terminar. $((. .)$.}

((Ruby sale; los otros niños empiezan a susurrar y copiar de los papeles uno al otro; cuando ella regresa de repente los niños se carcajean))

2 Ruby: Man nani- ((riendo con los otros)) Ustedes-

3 Mariana: Yang kop takras, [ent Amanda? Yo no estaba copiando, [verdad Amanda?

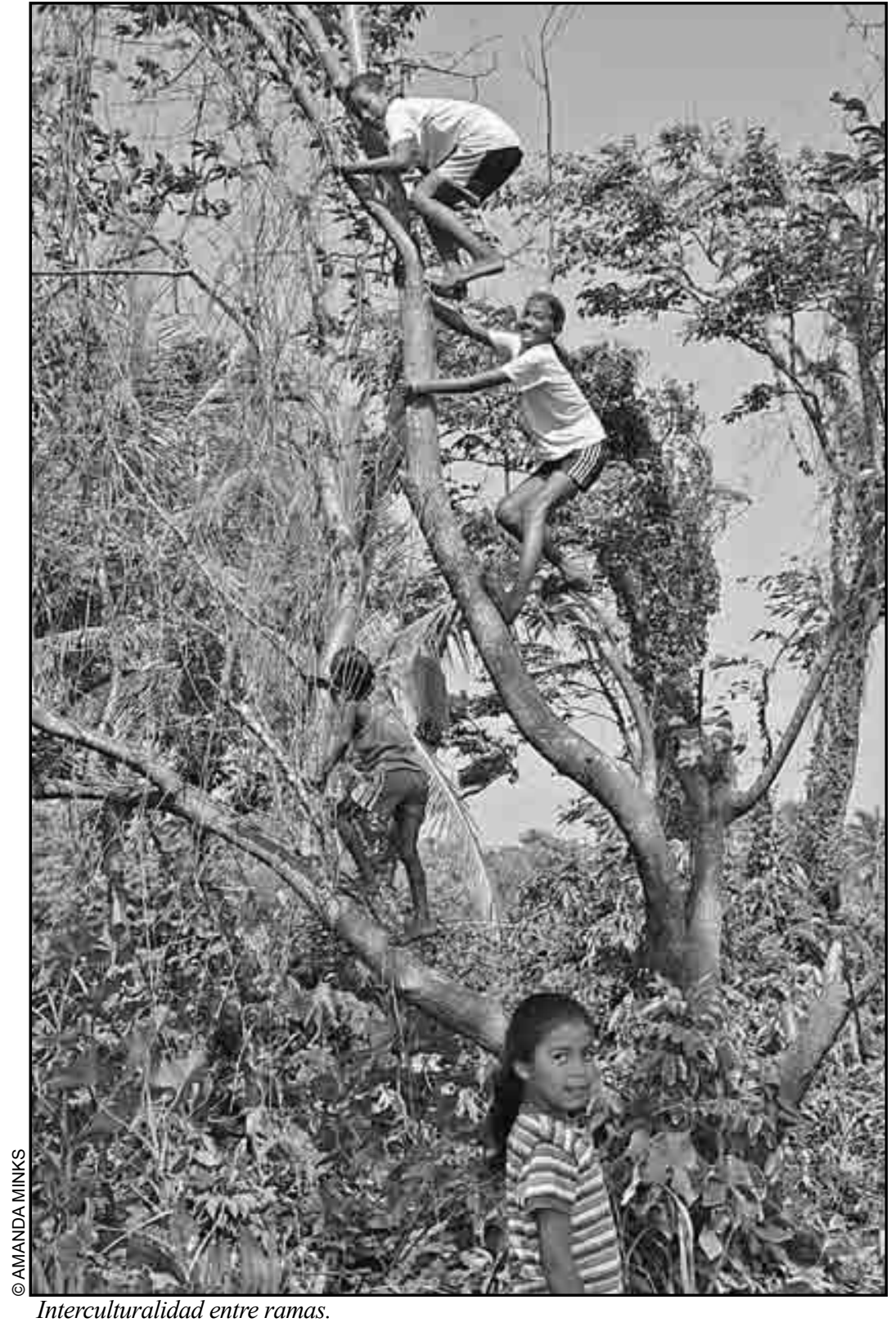

Interculturalidad entre ramas.
4 Ruby: [Man nani wal sut cero briaisma kop tak-

[Ustedes dos van a recibir cero por cop-

5 Coral: $\quad$ Ha-ah, los tres! Los tres, los tres, los tres estábamos copiando asi=

6 Lula: $=\underline{\text { YOno! }}$

7 Ruby: Yang balri ((riendo)) si Chavo bakYo vine ((riendo)) es como Chavo- 
8

¡Mariana! Man, man, naura bara, Coral

cuadernoka kat sma.

¡Mariana! Vos, vos, ahí cerca, estás al

lado del cuaderno de Coral.

\section{Coral: $\quad$ No lo copié.}

10 Ruby: Hhh. Iskiki sut prakan na nani setan kan.

Hhh. Yo no pude orinar estos ((chavalos)) estaban satanás ((mal comportados))

11 Coral: $\quad$ Yang iskiki ai daukras. Vaya, no

[vamos a copiar!

Yo no tengo ganas de orinar. Vaya, no

vamos a copiar!

12 Ruby: [iIsti!

[¡Rápido!

13 Coral: ((leyendo, con esfuerzo))

Comu-comunicación. Comu, ni,

14 Ruby: Bal, bal! Bal Mari, ¡vamo allá!

¡Vení, vení! Vení Mari, ¡vamos allá!

((moviendo a Mariana más lejos de los otros niños))

15 Mariana: Ent man nara [ai blikras!

No me mandas aquí, verdad!

16 Ruby: [Ah-ah, naura yang pleski ra kaha man, aha, [Uh-uh, vamos a mi lugar, vos, aja,

bukkam ni kop taki kapram mochilikam aik, Mariana.

estabas copiando con tu libro, dáme tu mochila Mariana.

18 Mariana: ¡Apia!

¡No!

19 Ruby: $\quad$ Ah-ah, [Mariana. Así no juego.

20 Mariana: [Ah-ah, yang brikaisna.

[Uh-uh, yo la voy a tener ((la mochila)).

21 Ruby: Den kaiki kaisna yang man naurkam ba
KAT man uba, Chilindrina baku,

Pues yo voy a estar mirando HASTA tus cosas vos sos muy, como la Chilindrina,

kop takaia baman.

sólo copias.

En esta transcripción, Ruby comienza hablando en español, pero la mayoría de su discurso está en miskito, aún cuando está realizando el papel de la Maestra Carluta. Los niños están leyendo de un texto en español de la escuela; este texto se trata de los medios de comunicación. No obstante adaptan el discurso español de la escuela al lenguaje miskito. Por ejemplo, en la línea 8 combinan cuaderno con el sufijo del estado constructivo en miskito " $k a$ ", para decir cuadernoka. En la línea 17 combinan mochila con el sufijo posesivo en miskito "kam" para decir mochilikam. El verbo compuesto kop takaia (copiar) podría ser una adaptación de copiar en español, copy en inglés, o los dos. Los niños usan el interrogativo final ent del inglés kriol cuando están hablando miskito (líneas 3 y 15), el cual es, particularmente, común entre miskito-hablantes en la RAAS.

A veces, los niños realizaron un efecto pragmático a través del cambio de códigos. Por ejemplo, en las líneas 1418, Ruby y Mariana están discutiendo en miskito dentro del marco del escenario del juego. Luego, en la línea 19, Ruby quiebra el marco del juego con una declaración en español: Así no juego, marcando un cambio para hablar como Ruby, no como la Maestra Carluta, y amenazando con terminar el juego. Cambiar al español en este contexto tiene el efecto de quebrar el discurso anterior para hacer un comentario "entre bastidores." Aquí vemos que el cambio mismo, no el lenguaje particular al cual se cambia, crea el efecto de quebrar el marco. Mientras el español se puede asociar con contextos escolares y el miskito con contextos familiares, en esta transcripción los niños están realizando el discurso escolar en miskito, y Ruby quiebra este marco de juego con una declaración en español. Este discurso trastorna una correlación sencilla entre el español y la escuela, por un lado, y el miskito y la casa por otro lado.

Cuando los niños tienen capacidad en varios lenguajes, usar un solo lenguaje también puede ser una acción significante. Coral tendía a usar principalmente español e inglés kriol en la mayoría de los contextos; y con frecuencia, cuando alguien le hablaba en miskito ella respondía en español o en inglés kriol. Sin embargo, en la línea 11, después de que Ruby hace una declaración 
en miskito (Iskiki sut prakan/ No pude orinar), Coral le responde en miskito (Yang iskiki ai daukras/ No tengo ganas de orinar). Parece que Coral funda su declaración en el habla anterior de Ruby, repitiendo la palabra miskita iskiki y ligando así las dos declaraciones. Considerando que Coral tendía a hablar español e inglés kriol, la interacción entre niños en este contexto fue un estímulo para practicar y aumentar su repertorio lingüístico en miskito.

Los niños miskitos en Corn Island con frecuencia mezclan y cambian lenguajes en su hablar cotidiano, sin pensar mucho en cuál palabra corresponde a tal idioma ( $¡$ a veces, un área borrosa aún para los lingüistas!). Los adultos miskitos no mezclan los idiomas tanto como los niños, pero generalmente no se oponen a la mezcla, como a veces pasa en los discursos puristas de la revitalización del lenguaje. La mezcla del miskito con otros idiomas es más común en los grados bajos de la escuela morava y en la interacción informal entre niños y jóvenes miskitos que han crecido en Corn Island.

Mientras los niños crecen aprenden distintos valores que son asociados a varias maneras de hablar en la casa, la escuela, la iglesia y lugares públicos. Con frecuencia, las ideologías locales proyectan jerarquías sociales en el lenguaje, y los niños miskitos sienten los efectos de ocupar los estratos bajos mientras sus familias luchan para sobrevivir y trabajar por un futuro mejor. Los niños que entonces asistían a la escuela pública estaban particularmente cautelosos en los contextos donde usaron miskito; no había clases en miskito en las escuelas públicas, y el uso del miskito tendía a marcar a los niños como intrusos en la isla.

El discurso de los niños, señalado anteriormente, trae a la memoria los estudios de niños latinos en los Estados Unidos, quienes combinan el inglés y el español en formas híbridas del lenguaje (Vásquez 1994; Zentella 1997; González 2001). Norma González, por ejemplo, ha escrito:

Tantas veces he escuchado de los adultos latinos que cuando eran niños fueron amonestados para hablar solamente el inglés en el patio de recreo y su pavor no expresado que de algún modo no serían capaces de distinguirlos. Mientras que los lenguajes sean borrosos, los contextos que evocan se entremezclan y combinan. (González 2001:50, mi traducción)

En la educación enfocada en la asimilación, particularmente en las generaciones del pasado, los niños en Nicaragua y en los Estados Unidos fueron enseñados a distinguir entre los lenguajes a través de castigos físicos y sicológicos cuando hablaban en un lenguaje prohibido. ${ }^{13}$ Hoy, la educación del lenguaje funciona más por ideología que por fuerza. Aunque las jerarquías culturales y socioeconómicas no han resultado en la asimilación total, los niños todavía experimentan las consecuencias negativas de hablar lenguajes marginados.

En 2003, una niña miskita, "Tasha," pasó unos meses en una clase bilingüe en inglés y español en la escuela pública en Corn Island. Ella no había crecido en la isla, y no tenía mucho conocimiento del inglés kriol o el inglés. Un día, cuando yo observaba la clase, los estudiantes leían en voz alta, en la pizarra, algunas oraciones. La profesora, que tendía a usar una variedad más conservadora (basilecto) de kriol, dijo a Tasha, "Yu no riidin" (Vos no estás leyendo). Tasha parecía apenada y dijo en español, "Yo no puedo." Un niño creole dijo "Apia" (no, en miskito). La profesora dijo, a manera de explicación, que Tasha era "miskito," y los otros niños repetían, "miskito, miskito". Un niño creole intentó imitar el habla miskita diciendo: "Miskito witin ra," y otro niño dijo: "Miskito yu haf tu laarn" (Miskito tenés que aprender). Luego, fuera de clase pregunté a Tasha si le gustaría estar en la clase de la mañana, la cual tenía varios niños miskitos y donde el lenguaje de enseñanza era español. Ella me dijo que no, quería aprender el inglés, entonces se quedaría en la clase de inglés. Sin embargo, pocos meses más tarde, ella abandonó la escuela totalmente.

Para algunos niños miskitos, el multilingüismo creó nuevas posibilidades de identificación intercultural, pero esto no necesariamente resultó en la movilidad socioeconómica en Corn Island. Las consecuencias del uso innovador del lenguaje pueden tener limitaciones parecidas a las de la educación intercultural-bilingüe, las cuales notaron Galío Gurdián y Danilo Salamanca hace muchos años: "solo un programa educativo no puede vencer las fuerzas económicas y políticas que van en otra dirección" (Gurdián y Salamanca 1991:11).

13 Irónicamente, la idea de los lenguajes rodeados e internamente homogéneos existiendo en contextos separados sostiene la educación asimilacionista además de los planteamientos dominantes de la revitalización lingüística. Agradezco a Jane Freeland por hacer esta observación en sus comentarios sobre este artículo. 


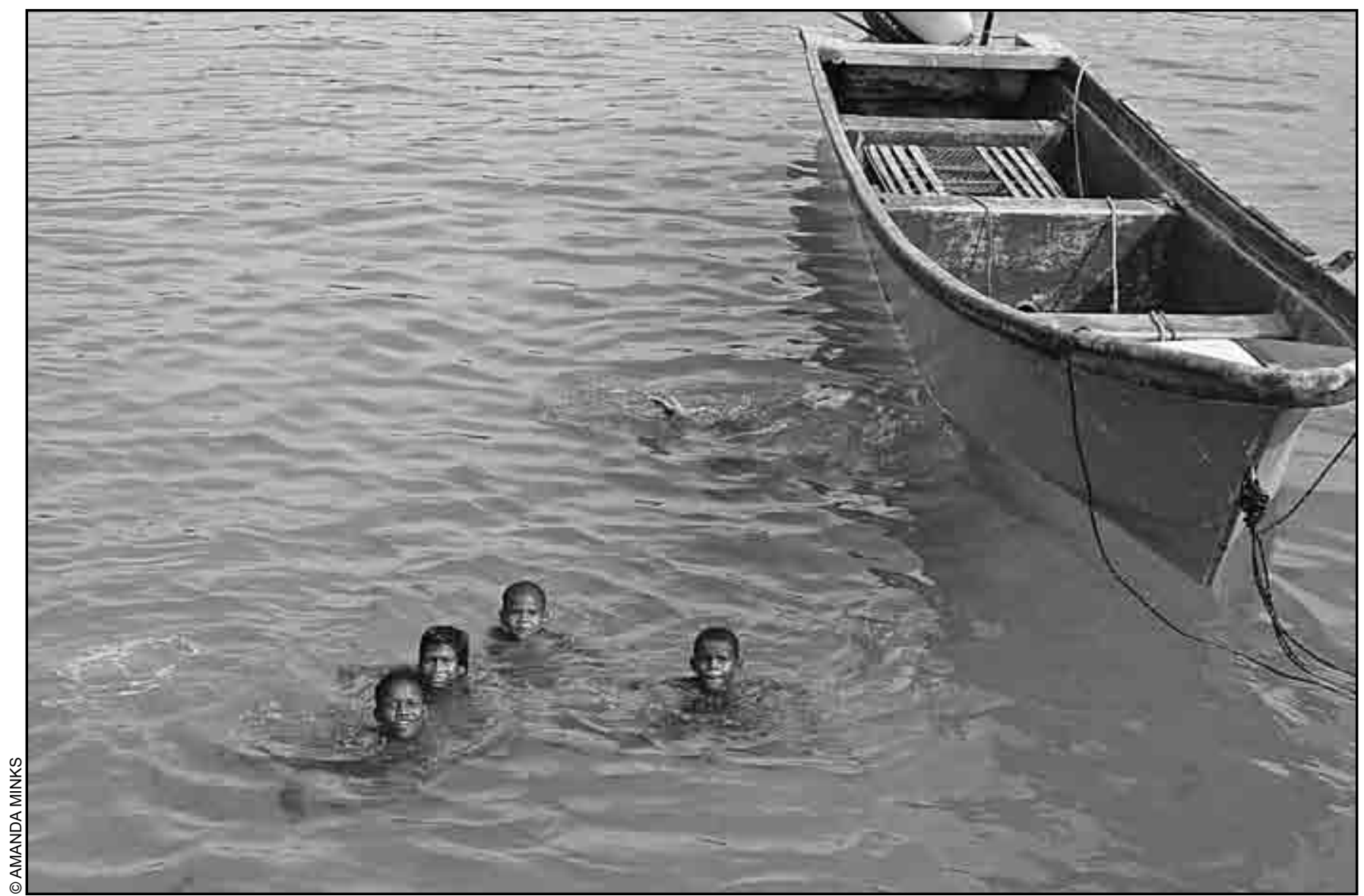

Gozando de un baño en aguas de Corn Island.

\section{Sentidos interculturales}

Enero, 2009. Llegué a Corn Island para una visita el domingo en la mañana, justo a la hora de la escuela dominical en la iglesia morava. Hacía un año y medio que yo no había visitado la isla, y los niños habían crecido mucho desde la última vez que los vi. Coral había llegado a ser una joven bonita y estaba casi tan alta como yo. Ella me saludó en español, pero en la iglesia cantamos juntas en miskito el himnario miskito. El lenguaje más prominente de la iglesia morava todavía era el miskito. Más tarde pregunté a Coral si entendía todo lo que dijeron en la iglesia, y dijo que entendió la mayoría, sólo algunas palabras le eran desconocidas. Otra joven de la familia tenía menos capacidad en el miskito que Coral, pero ella también parecía entender el discurso miskito durante el culto, y se levantó en el momento apropiado para leer en voz alta la Biblia en español. Esto era común; la mayoría de los jóvenes y adultos menores tenían Biblias en español, mientras que los ancianos tenían Biblias en miskito. La Biblia en español era más accesible para comprar, y los jóvenes dijeron que les ayudaba a perfeccionar sus habilidades del alfabeto en español.
Las prácticas lingüísticas en la iglesia demostraron solo un lado de la situación. Al día siguiente fui a nadar con un grupo de niños de esta misma familia. Durante mi breve visita, yo había escuchado a los niños mayores hablando principalmente español entre ellos. Sin embargo, mientras jugaban alborotadamente en el mar usaron más miskito e inglés kriol, además del español. Coral también hablaba bastante miskito, chapoteando y persiguiendo a los otros niños, usando el discurso multilingüe del juego que todavía era común en Brig Bay.

La gente miskita todavía ocupaba una posición vulnerable en Corn Island, aunque la política local y regional había cambiado desde 2002. En las elecciones municipales de noviembre de 2008 resultó electa una vice-alcaldesa miskita por primera vez en Corn Island. No obstante, la historia reciente sugiere que solo la representación étnica no siempre mejora las condiciones de los sectores más pobres de la sociedad. Siempre hay trabajo por hacer en el ámbito de la práctica cotidiana: la comunicación, el intercambio, el diálogo respetuoso, los derechos iguales y la participación democrática. Una perspectiva intercultural destaca la interdependencia de los grupos de personas y las 
maneras en que las diferencias surgen a través de la lucha interactiva. Como escribió Alejandro Grimson: "Para que existan disputas debe existir algo compartido, al mismo tiempo que aquello que es compartido se forja a través del mismo conflicto" (2000:54).

La práctica cotidiana de la interculturalidad incluye la revitalización lingüística y el fortalecimiento de lo propio, pero también incluye maneras creativas de hablar lenguajes múltiples y participar en comunidades diversas y medios globales de comunicación. A través de su interacción con personas y lenguajes diversos en Corn Island, los niños miskitos han desarrollado modos multilingües de hablar. Ellos se han identificado como isleños miskitos que hablan no sólo el miskito sino también el inglés kriol y el español. Aunque su residencia física en Corn Island con frecuencia ha sido amenazada, ellos han desarrollado sentido de pertenecer socialmente a través de sus multilingües prácticas expresivas.

En años recientes, la documentación y revitalización de los lenguajes costeños han sido proyectos sumamente importantes, realizados por investigadores visionarios costeños y extranjeros. La creación de diccionarios y gramáticas ayuda a preservar los idiomas para las generaciones del futuro, y apoya su legitimación en discursos nacionales e internacionales dado que manifiestan sus sistemas complejos. Este trabajo se puede complementar con más atención al uso del lenguaje en la interacción cotidiana, revelando hábitos reales de comunicación los cuales pueden ser un fundamento para entender y promover el mantenimiento del lenguaje, además de desarrollar nuevos programas educativos, como ha escrito Jane Freeland:

Los programas interculturales-bilingües "estándares," que parten de la diferencia del lenguaje y enfatizan la educación formal y el alfabetismo, tienden a tratar los lenguajes como sistemas abstractos, y no en términos de cómo la gente usa los lenguajes en la interacción. De ahí viene una necesidad de codificación, ortología ("graphisation") y estandardización, y un enfoque de investigaciones a describir los sistemas formales descontextualizados. Por lo menos tan necesario es un entendimiento sociolingüístico de los repertorios multilingües que surgen de las prácticas interculturales, la manera en que funciona como un instrumento eficaz y en la construcción de identidades, y cómo desarrollar mejor estos repertorios a través de la educación. (Freeland 2003:253, mi traducción; también véase Freeland 2004:40)

Yo creo que la socialización, que educa una amplia gama de capacidades lingüísticas, puede apoyar la revitalización lingüística. El respeto para el conocimiento de los ancianos todavía es fundamental, pero su relevancia en el mundo actual puede ser re-imaginado a través de nuevas formas de comunicación. Por ejemplo, la diversidad interna del idioma miskito, incluyendo sus estructuras para adaptar los préstamos de otros idiomas, es una ventaja para desarrollar las habilidades multilingües. Los medios locales y regionales de comunicación también pueden ser una herramienta poderosa para fortalecer a las comunidades y hacer un puente entre formas distintas del conocimiento, como hemos aprendido de los programas comunitarios de la radio y la televisión (Antonio 2007). Aún cuando las comunidades no tienen aportes a los medios de comunicación desarrollan modos creativos para participar en los medios que vienen desde lejos. Los proyectos de revitalización cultural pueden aprovecharse de las experiencias que los niños han tenido con los medios de comunicación y tratar la relación entre diferentes formas de conocimiento y expresión.

La educación intercultural-bilingüe ha sido una fuerza poderosa en la Costa Caribe desde los años 1980, promoviendo la autonomía regional, el diálogo respetuoso y el orgullo en la herencia cultural. Continúa la institucionalización de la EIB en algunas comunidades, mientras que en otras hacen falta fondos y recursos. Esta situación puede ser una oportunidad para buscar en las comunidades de la Costa los recursos culturales y las herramientas expresivas que pueden promover los cambios sociales y políticos. Los niños con frecuencia cruzan los límites culturales y lingüísticos más fácilmente que los mayores. Sus formas interculturales de expresión y pertenencia pueden ofrecer lecciones para todos nosotros - por ejemplo, el reconocimiento que hay de maneras comunes de comunicarse entre diferentes grupos de personas, y hay maneras diferentes de comunicarse entre miembros de la misma familia. Las habilidades multilingües, combinadas con una disposición para el diálogo, son herramientas importantes para promover la comunicación entre los grupos sociales y culturales, con el fin de encontrar un espacio común y vivir juntos en la diversidad. 


\section{Agradecimientos}

Agradezco a Alvaro Rivas por invitarme a presentar un artículo en WANI y por esperar con paciencia tres años antes de recibirlo; Danilo Salamanca y Gizaneta Fonseca también han facilitado la publicación. La versión final de este artículo se mejoró por las sugerencias de Jane Freeland, Mark Jamieson y Danilo Salamanca. Otros investigadores de la Costa Caribe que han compartido sus conocimientos con generosidad incluyen a Margarita Antonio, Elena Benedicto, Lole García, Edmundo Gordon, Charles Hale, Melvin James, Eloise Howell, Arja Koskinen, Ruth Matamoros, Guillermo McLean, Karl Offen, Melesio Peter, Ruth Rouvier, Barnabás Waldán y Fidel Wilson. Mis investigaciones en Corn Island en 2002 y 2003 recibieron apoyo económico de las siguientes organizaciones: Social Science Research Council, WennerGren Foundation, Tinker Foundation y Fulbright Institute of International Education. Realicé las investigaciones en afiliación con el Instituto de Promoción e Investigación Lingüística y Rescate Cultural (IPILC) de URACCAN. En Corn Island, la profesora trilingüe y talentosa Angela Abraham fue una colaboradora y amiga preciosa, quien me ayudó a transcribir, traducir e interpretar el discurso de los niños. Me gustaría agradecer a las familias que me han recibido en sus casas por corto y largo plazo en Nicaragua. Agradezco muchísimo a todos los niños que participaron en estas investigaciones por su tolerancia, amistad e imaginación. Alvaro Baca Rodríguez me ayudó con la traducción de este artículo al español y con muchas otras cosas. Cualquier error que aparezca en este artículo es mi responsabilidad.

\section{Bibliografía}

Acuña Roque, Claudia Cecilia, Marlene de los Ángeles Méndez López, y Romer Altamirano Guerrero. 2002. Plan de Ordenamiento Ambiental del Municipio de Corn Island. Managua: ASDI, MARENA, INETER.

Antonio, Margarita. 2007. "Conceptos de Autonomía e Identidad en al discurso de las radios de Bilwi durante las Elecciones Regionales 2006." Tesis de maestría en antropología social, URACCAN.

Cox, Avelino. 1998. Cosmovisión de los pueblos de Tulu Walpa. Según relatos de los sabios ancianos miskitos. Managua: URACCAN.

FOREIBCA-IPILC/URACCAN. 2003. You Can Read and Write Kriol. Bluefields, Nicaragua.

Freeland, Jane. 1993. “'I am a Creole, So I Speak English’: Cultural Ambiguity and the English/Spanish BilingualBicultural Programme of Nicaragua's Atlantic Coast." En Language and Culture, ed. D. Graddol, L. Thompson y M. Byram, 71-83. Clevedon: BAAL and Multilingual Matters.

------. 1995. “' 'Why Go to School to Learn Miskitu?': Changing Constructs of Bilingualism, Education, and Literacy among the Miskitu of Nicaragua's Atlantic Coast." International Journal of Education and Development 15(2): 245-61.

-----. 2003. "Intercultural-bilingual Education for an Interethnic-Plurilingual Society? The Case of Nicaragua's Caribbean Coast." Comparative Education 39(2): 239-60.

-----. 2004. "La Educación Intercultural-Bilingüe y su relación con las prácticas interétnicas y plurilingües de la Costa Caribe Nicaragüense." WANI 39:25-43.

Fuller, Norma. 2002. Interculturalidad y política: desafios y posibilidades. Lima: Red para el desarrollo de las ciencias sociales en Perú.

García, María Elena. 2005. Making Indigenous Citizens: Identity, Development, and

Multicultural Activism in Peru. Stanford: Stanford University Press.

García Canclini, Nestor. 1995. Hybrid Cultures: Strategies for Entering and Leaving

Modernity. Minneapolis: University of Minnesota Press.

--------. 2004. Diferentes, desiguales y deconectados: Mapas de la interculturalidad. Barcelona: Gedisa Editorial.

Godenzzi, Juan Carlos, ed. 1996. Educación e interculturalidad en los Andes y la Amazonia.

Cuzco: Centro de Estudios Andinos "Bartolomé de las Casas."

González, Norma. 2001. I Am My Language: Discourses of Women and Children in the Borderlands. Tucson: University of Arizona Press.

Gordon, Edmund 1998. Disparate Diasporas: Identity and Politics in an African Nicaraguan Community. Austin: University of Texas Press.

Gould, Jeffrey. 1998. To Die in This Way: Nicaraguan Indians and the Myth of Mestizaje, 1860

-1965. Durham, North Carolina: Duke University Press. 
Grimson, Alejandro. 2000. Interculturalidad y comunicación. Bogotá: Grupo Editorial Norma.

Gurdián, Galio and Danilo Salamanca. 1991. “Autonomía y educación bilingüe.” Wani 9:1-14.

Hale, Charles. 2005. "Neoliberal Multiculturalism: The Remaking of Cultural Rights and Racial

Dominance in Central America." PoLAR: Political and Legal Anthropology Review 28(1):10-28.

Heise, María. 2001. Interculturalidad: Creación de un concepto y desarrollo de una actitud. Lima: Forte.

Holm, John. 1978. The Creole English of Nicaragua's Miskito coast: its Sociolinguistic History and a Comparative Study of its Lexicon and Syntax. Tesis PhD, University College London.

Jamieson, Mark. 1995. Kinship and Gender as Political Processes among the Miskitu of

Eastern Nicaragua. Tesis PhD, University of London.

-------. 1999. “El inglés y la variedad de miskito en la cuenca de Laguna de Perlas.” Wani 24:22-32.

-------. 2001. "Masks and Madness: Ritual Expressions of the Transition to Adulthood

among Miskitu Adolescents."Social Anthropology 9(2): 253-68.

-------. 2007. "Language and the Process of Socialisation amongst Bilingual Children in a Nicaraguan Village." Durham Anthropology Journal 14(1).

Kelly, Reverend Edward. Sin fecha. Diary. Texto de los archivos del Reverendo Rodwell Morgan.

Khan, Aisha. 2001. "Journey to the Center of the Earth: The Caribbean as Master Symbol." Cultural Anthropology 16(3):271-302.

Minks, Amanda. 2008. "Performing Gender in Song Games among Nicaraguan Miskitu

Children." Language and Communication 28:36-56.

------. 2007. “'Goblins Like to Hear Stories': Miskitu Children's Narratives of Spirit

Encounters." En Selves and Identities in Narrative and Discourse, ed. Michael Bamberg, Anna

DeFina, and Deborah Schiffrin, pp. 9-40. Amsterdam: John Benjamins.

-------. 2006a. "Mediated Intertextuality in Pretend Play among Nicaraguan Miskitu Children."

Texas Linguistic Forum (SALSA) 49:117-127.

------. 2006b. Interculturality in Play and Performance: Miskitu Children's Expressive

Practices on the Caribbean Coast of Nicaragua. Tésis Ph.D., Columbia University.

Offen, Karl. 1999. The Miskitu Kingdom: Landscape and the Emergence of a Miskitu Ethnic Identity, Northeastern Nicaragua and Honduras, 1600-1800. Tésis Ph.D., University of Texas, Austin.

Palmié, Stephan. 2006. "Creolization and its Discontents." Annual Review of Anthropology 35: 433-56.

Postero, Nancy. 2006. Now We Are Citizens: Indigenous Politics in Postmulticultural Bolivia.

Stanford: Stanford University Press.

Rappaport, Joanne. 2005. Intercultural Utopias: Public Intellectuals, Cultural Experimentation, and Ethnic Pluralism in Colombia. Durham y London: Duke University Press.

Tubino, Fidel. 2002. "Entre el multiculturalismo y la interculturalidad: más allá de la discriminación positiva." En Interculturalidad y política: desafios y posibilidades.

Ed. Norma Fuller, 51-76. Lima: Red para el desarrollo de las ciencias sociales en Perú.

Vásquez, Olga, Lucinda Pease-Alvarez, and Sheila Shannon. 1994. Pushing Boundaries:

Language and Culture in a Mexicano Community. Cambridge: Cambridge University Press.

Walsh, Catherine. 2006. "Interculturalidad y colonialidad del poder: Un pensamiento y posicionamiento otro desde la diferencia colonial." En Interculturalidad, descolonialización del estado y del conocimiento, ed. Catherine Walsh, Walter Mignolo y Álvaro García Linera. Buenos Aires: Ediciones del Signo.

Wolfe, Justin. 2007. The Everyday Nation-State: Community \& Ethnicity in Nineteenth-Century

Nicaragua. Lincoln and London: University of Nebraska Press.

Youssef, Valerie. 1996. "Varilingualism: the Competence Underlying Codemixing in Trinidad and Tobago." Journal of Pidgin and Creole Languages 11(1):1-22.

Zentella, Ana Celia. 1997. Growing up Bilingual: Puerto Rican Children in New York. Oxford: Blackwell. 